ISSN: 2172-9077

https://doi.org/10.14201/fjc201714147166

\title{
LA POÉTICA CLAUSTROFÓBICA DE LOS NO-HOGARES EN REPULSIÓN (ROMAN POLANSKI, 1965)
}

\section{The Claustrophobic Poetics of the Non-Homes in Repulsion (Roman Polanski, 1965)}

Ldo. Alberto Román PADILLA DÍAZ

Personal Investigador en Formación - Universidad de Córdoba, España.

E-mail: alberpd@hotmail.com

(1D http://orcid.org/0000-0002-2753-733X

Fecha de recepción del artículo: 13/04/2016

Fecha de aceptación definitiva: 10/01/2017

\begin{abstract}
RESUMEN
La vinculación de una escenografía cerrada y claustrofóbica con respecto a la desequilibrada psique de unas protagonistas femeninas al borde de la locura, es una constante en las películas de Terror Psicológico. Sin embargo, en los films de Roman Polanski, esta constante se convierte en obsesión y lugar común de gran parte de su filmografía. Llegando a crearse una especie de original estilema fundamentado en re-encuadres, oscuras iluminaciones y otras transformaciones arquitectónicas de gran interés y cierta semiología y que podríamos denominar como Poética de lo claustrofóbico. El presente escrito se propone indagar en los significantes y significados que dan unidad a este dispositivo escenográfico-psicológico del director francés, a través del segundo film de su carrera: «Repulsión» (1965).
\end{abstract}

Palabras clave: «No-hogan»; Repulsión; Re-encuadre; Mundo interior; « Poética claustrofóbica»; Polanski.

\begin{abstract}
The link between closed and claustrophobic scenery and the twisted mind of the female main characters and their unbalanced psyches is a constant feature in psychological terror movies. Nevertheless, in Roman Polanski's films, it becomes an obsession which is commonplace throughout his movies. A type of original style is created based on resettings, dark lightings and other architectural transformations of great interest and some semiology, which we might label claustrophobic poetics. The purpose of this paper is to investigate the significance of the scenographicpsychological device of the French director throughout his second film, Repulsion (1965).
\end{abstract}

Keywords: Non-home; Repulsion; Trimming; Interior World; Claustrophobic poetry; Polanski 


\section{El No-Hogar de Carole Ledoux}

\subsection{INTRODUCCIÓN AL No-HogAR de CAROLE LEDOUX}

El escenario-vivienda que rodea a varias de las películas de Roman Polanski no es solo un mero decorado testigo de las desventuras psicológicas de sus habitantes, sino un «personaje» más de la propia película, como lo es también la casa «Cumbres Borrascosas» de la novela del mismo nombre de Emily Brontë o la mansión «Manderley» de «Rebeca» llevada al cine en 1940 por Alfred Hitchcock.

Como suele darse en este tipo de estudios, se hace necesaria la concesión o licencia de un nuevo concepto que defina bien los espacios en los que transcurren muchas de las películas de Polanski. En este caso concreto, la trilogía conformada por «Repulsión», «La Semilla del Diablo» y «El quimérico Inquilino». Si bien dicho nombre de la trilogía, aunque no está mal adjudicado, la designación solo hace referencia al actante espacial que tienen en común los tres films, pero no su malsana e inextricable atmósfera. Es entonces cuando la obra de Marc Augé «Los No-Lugares: Espacios de la sobremodernidad» hace acto de presencia.

En ella, Augé habla de los «No-Lugares», espacios que no son ni de relación con la persona que los habita y que no poseen identidad con la misma:

Si un lugar puede definirse como lugar de identidad, relacional e histórico, un espacio que no puede definirse ni como espacio de identidad ni como relacional ni como histórico, definirá un no lugar. [...] espacios que no son en sí lugares antropológicos $[\ldots]$ no integran los lugares antiguos $[\ldots]$ ocupan un lugar circunscripto y específico. (Augé, 1992, p. 83).

Son espacios de paso que debido a la «sobre-modernidad» actual de la que Augé habla en su ensayo da lugar a un nuevo tipo de soledad, aislamiento y angustia silenciosa (incomunicación). Sensaciones exactamente iguales a la que se producen en las viviendas de estos films posteriores ${ }^{1}$ también dirigidos por Polanski, pero con una variación significativa: no estamos hablando de lugares, sino de hogares. Sus protagonistas tratarán de completar ese vacío espacial con su propia identidad, mediante sus decoraciones preferidas o proyectos personales. Pero en su intención por lograr esta comunión «hogar-habitante» se toparán con la llegada de un elemento no deseado, una situación agobiante o una presencia que hará que erren en el intento. En el caso de «Repulsión», la presencia masculina que tanto repudia la protagonista Carole Ledoux (Catherine Deneuve).

De las tres películas que conforman la trilogía antes citada, «Repulsión» vendría a ser el caso más significativo e ilustrativo de la opresiva atmósfera que podríamos denominar como «poética de lo claustrofóbico». El programa escenográfico de elementos y formas materiales que rodean el «Nohogar» de Carole está repleto de evidentes, e incluso obvias metáforas psicosexuales (espejos, ruidos, etc.) que «aprisionan» mental y cinematográficamente a la muchacha. Pese a las características oníricas, surrealistas y, sobre todo, típicas de una percepción dañada, existe un circuito o «dispositivo escenográfico-psicológico» bien armado y articulado que evoluciona a lo largo del hundimiento del mundo interior de la protagonista. Desarmaremos este dispositivo mediante el análisis de determinadas secuencias. Un mundo interior cerrado y condensado en las cuatro paredes de este malsano apartamento. 


\subsection{Metodología}

En la realización de este ensayo se ha recurrido al tradicional análisis fílmico de aquellas secuencias del film en las que el «dispositivo escenográfico-psicológico» antes mencionado, se aprecia de manera más clara. Las secuencias están ordenadas de forma cronológica con el fin de lograr un acercamiento más didáctico hacia la película, pero sobre todo para demostrar cómo cada clave espacial del film va evolucionando hasta conseguir esa vinculación de la escenografía del apartamento con la mentalidad perturbada de la protagonista que en él vive. Ya que en un análisis al igual que cuando se ve una película una vez «nuestros ojos y cerebros son más aptos para advertir las diferencias que para concentrarse en estímulos uniformes y prolongados» (Bordwell y Thompson, 1979, p. 163).

La escenografía aquí estudiada no hace referencia únicamente al conjunto de decorados o arquitectura propiamente dicha -o por lo menos no a la mera citación de estos-, sino a las claves, significantes y significados de los mismos. A su vez se tendrán en cuenta a lo largo de análisis parámetros como los sonidos o los re-encuadres; siempre en relación a como estos manipulen o condicionen el marco escenográfico.

En lo que atañe al marco teórico, este estudio se fundamenta en los trabajos más significativos sobre la teoría del cine, en particular, sobre la forma que tiene el director de captar el espacio o dar significado a un espacio concreto en una secuencia determinada. Cabe señalar que no son necesariamente historiadores, teóricos o filósofos de la imagen los que han situado a Roman Polanski entre sus especialidades. El presente ensayo también toma en cuenta lo que tienen que decir otras voces importantes de la teoría del cine sobre la forma que tiene el director de captar el espacio o dar significado a tal espacio en tal secuencia. Pero no necesariamente, historiadores, teóricos o filósofos de la imagen que tengan situado a Roman Polanski entre sus especialidades. Desde historiadores clave para el estudio de la historia del cine (Serguei M. Eisenstein) a recientes teóricos españoles de la obra de Polanski (Diego Moldes o María López Villarquide). Aunque, sin duda, también ha sido de gran ayuda el riguroso estudio sobre la escenografía de Santiago Vila, cuyo análisis de escenas - pese a que ninguna en concreto pertenezca a un film de Polanksi- para su tesis doctoral «La Escenografía: Cine y Arquitectura» (1997) ha contribuido mucho para dar cuerpo y forma a las explicaciones sobre «Repulsión» aquí aportadas. Sin embargo, el enfoque y la terminología obedecen más a un estudio de Historia del Arte que a uno de Arquitectura, rama en la que Vila es catedrático. También se ha establecido un marco teórico para aquellos matices como el montaje, los sonidos o el uso de re-encuadres. Factores que, si bien y por defecto, no son parte de la escenografía como tal, pero que sí inciden notablemente en la misma. Recurriendo por ejemplo a los historiadores David Bordwell y Kristin Thompson para abordar este lenguaje.

\section{PRESENTACIÓN: INVASIÓN SONORA DEL NO-HOGAR EN FUTURA DESCOMPOSICIÓN}

Para empezar, se analizará la primera y muy sonora escena de la llegada de Carole al apartamento. Carole llega al hogar tras una jornada de trabajo. En primer término y desde el suelo, se aprecia el plano detalle en el que Carole se deshace de los tacones dejando los pies desnudos una acción que a algunos historiadores le evoca al fetichismo de Alfred Hitchcock:

Otro de los temas recurrentes en «Repulsión» que la acercan irremediablemente a «Vértigo» es el impulso fetichista que transmite la mirada obsesiva de la cámara, y, por ende, nuestra propia mirada. Toda la escena del regreso de Carole del Salón de Belleza es rodada por Polanski a ras de suelo; vemos las piernas cami- 
nar hasta el salón situado al fondo y a medida que se aleja, descubrimos su cuerpo al completo, gracias a la profundidad de campo [...] Ella se descalza -fetichismo de los pies, como en Hitchcock, recuérdese el plano de los pies desnudos de Madeleine en «Vértigo»- de espaldas a la cámara [...] se quita la falda y vemos su combinación blanca - símbolo de pureza- , se aproxima a la ventana y mira hacia la calle. (Moldes, 2004, p. 155).

Desde el primer minuto que el espectador se adentra en ese apartamento, ya aprecia cómo los sonidos emitidos desde el exterior son vistos como una especie de invasión, con lo que subraya el carácter de refugio de ese mundo exterior masculino del que Carole se protege. La protagonista se acerca al cristal de donde proceden los ruidos, y desde esa perspectiva (Foto 1), observa a las monjas que están jugando y que, al ser vistas desde dicho ángulo, se muestran con distancia y poco cercanas. Sentimientos remarcados por el melancólico rostro de Carole al no poder acceder a esa realidad de «vida pura y sin hombres». El espectador es solo un mero observador, y al igual que Carole, queda relegado a estar en ese estado intermedio -cuya forma figurada en escena sería el apartamento- entre la pureza del convento vecino y la repulsión masculina que acecha el «no-hogar».

Al minuto se dirige al baño (Foto 2) -espacio en el que se «limpia» de la «realidad masculina de afuera» - , pero la navaja y otros útiles de higiene del amante de la hermana son el primer signo de invasión (masculina), dando lugar a la primera tensión repulsivo-sexual entre Carole y Michael, el amante de su hermana Helen.
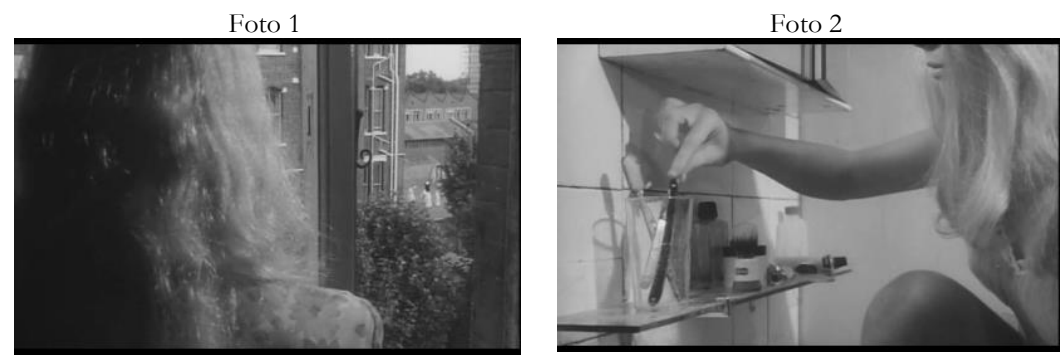

Fuente: Capturas de pantalla del DVD de «Repulsión».

Edición «Fnac». Distribuidora «Avalon».

Durante la secuencia, suena el timbre y con el mismo se produce la entrada de Michael en escena. Junto a esta segunda intromisión sonora se escucha también el tañido de las campanas del convento. Este ruido de campanas es, cuanto menos, admonitorio, ya que también suena hacia el tramo final del film, cuando el cobrador de impuestos viene a visitar a Carole, para luego intentar violarla. En esta escena concreta que estamos analizando, Michael hace bromas con claras indirectas sexuales hacia Helen. Por ello cabe entender que ese molesto son enfatiza las pulsiones sexuales por parte de los hombres que irrumpen en ese apartamento puesto que «es mediante [...] el tañido de sus campanas como la realidad del mundo exterior pretende penetrar en la realidad física del mundo interior de Carole, simbolizada en el carácter de refugio que adquiere su piso» (Latorre, 1998, P.19).

Esta configuración de sonidos, así como la interpretación de la misma, contribuye no solo a otorgar un realismo necesario a la secuencia, sino que como diría Pudovkin, contribuye notablemente «is to augment the potential expressiveness of the film's content» (Sargeant, 2001, p. 142); en este caso concreto, el contenido de una serie de operadores escenográficos (timbres y campanas). 
En un instante de la misma secuencia, se comienza a mostrar una de las características principales del dispositivo que podríamos denominar como «poética claustrofóbica». Esta «poética» hace referencia a la obsesión de las imágenes por conseguir que hasta el espacio más abierto termine pareciendo una «prisión» a nivel externo e interno.

Volviendo a la secuencia, esta obsesión visual se ve reflejada en el breve minuto en el que, acercándose a la salida, la imagen muestra a la protagonista de espaldas, mientras que, a su vez, las sombras romboidales de los marcos de la puerta y alguna ventana conforman una especie de «jaula» que «atrapa» a la protagonista (Foto 3) - inscripción del «micro-infierno» mental del personaje.

La cámara se toma su tiempo y recorre el apartamento, mostrando los detalles más significativos de la escenografía, rica especialmente en decoración de regusto «naif» (Foto 4). Lo que puede ser interpretado sencillamente como un mero gusto decorativo, aunque no es descartable la idea de que se trate de una forma de aludir el inocente carácter de Carole.
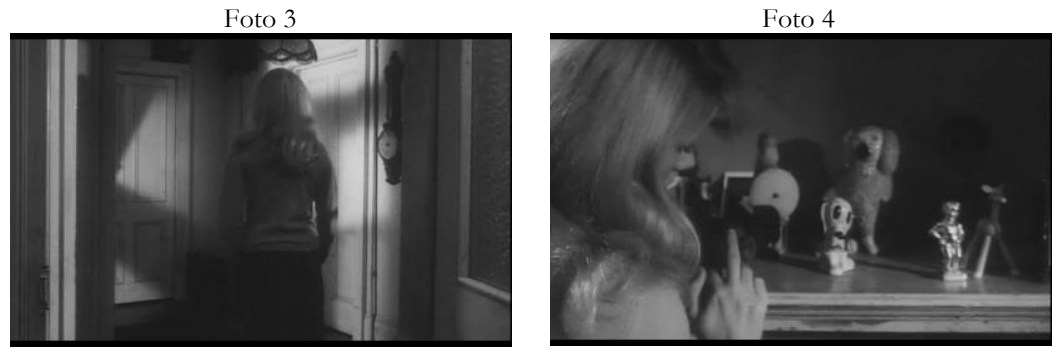

Fuente: Capturas de pantalla del DVD de «Repulsión». Edición «Fnac». Distribuidora «Avalon».

La imagen pasa a un fundido a negro. Llega la noche y mediante una serie de planos, se nos presenta una de las habitaciones más importantes del apartamento: el cuarto de Carole. En primer término, vemos la ventana que da vistas a ese convento de «vida pura» antes citado. Inmediatamente después se introducen en la banda sonora las risas de excitación del cuarto de al lado. Dicho cuarto es el cuarto de Helen, quien ahora está intimando con Michael. La cámara capta planos de determinados elementos de la habitación de Carole que luego adquirirán relevancia en el film, como la lámpara, cuyo detalle se verá hacia el final del trabajo.

Foto 5

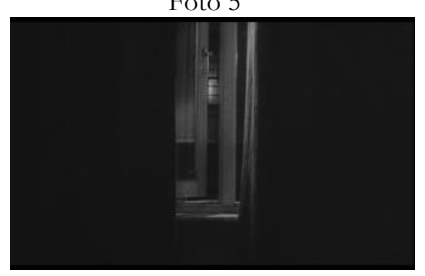

Foto 6

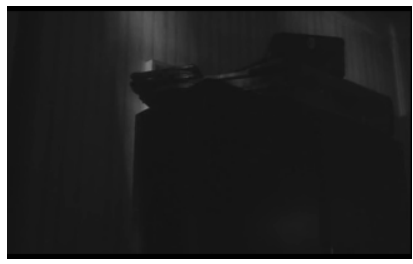

Foto 7

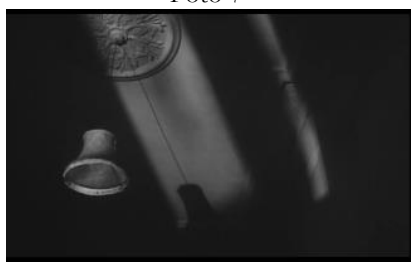

Fuente: Capturas de pantalla del DVD de «Repulsión». Edición «Fnac». Distribuidora «Avalon».

Conforme pasan dichos planos (Fotos 5, 6 y 7), las risas se van transformando progresivamente en orgasmos. Estos acaban dominando la sonoridad de toda la habitación de Carole y esta, resignada, apenas concilia el sueño. De ahí el empleo de los planos, para demostrar cómo la propia decoración se «contamina» de la esencia masculina. La masculinidad, en su concepción sonora, ya domina la habita-

(C) Ediciones Universidad de Salamanca / CC BY - NC ND Fonseca, Journal of Communication, n. 14, 2017, pp. 147-166 
ción más íntima del «no-hogar». A pesar de que la acción ocurra fuera del campo de la imagen cinematográfica que se ve en pantalla, los sucesos de ambos espacios están encadenados irrefutablemente; entendiendo el «fuera de campo» como aquel «Espacio que se constituye como discurso o texto, puesto que se funda en una relación significante entre una imagen visualmente presente y otra ausente, significada» (Vila, 1997, p. 32). Además del «fuera de campo» asistimos así a un relevante uso del montaje a base de asociaciones de ideas y elementos espaciales. La lectura de dichas ideas es más clásica que las del modelo «Eisentiniano», pero no por ello menos efectiva, pues entre el sonido y la convincente unión de este con los planos concretos de la decoración, el espectador advierte el «contagio masculino» de la habitación. Al respecto, cabe mencionar, al director y teórico ruso:

El montaje tiene una doble función como vehículo tanto de la narración descriptiva como de la imagen generalizada, siempre que, una vez más, el montaje se relacione con la obra de arte. [...] también existen sus definiciones «puramente formales», tales como la repetición de una cierta combinación o agrupación a intervalos de tiempo fijos e iguales: el juego alternativo entre larga y breve, acentuada y no acentuada, etc... La función descriptiva de un fragmento reside ante todo en tener la duración adecuada y la construcción rítmica está siempre acosada por la cauta preocupación de no perder el elemento narrativo e ilustrativo, de no «cortar» la función descriptiva del fragmento. (Eisenstein, 2001, pp. 11-13).

Mencionar, aunque sea brevemente, a Eisenstein en asuntos de montaje implica indagar un poco en su trascendental teoría del montaje cinematográfico (el párrafo citado proviene de la misma), porque, fundamentalmente, es lo que se efectúa en la toma en imágenes de este instante. La escena juega con la repetición de intervalos de tiempo (cada plano, desde que el sonido orgásmico inunda la habitación, dura exactamente lo mismo) lo que hace que ni los motivos e ideas fijas formales (todos los útiles e inmuebles del cuarto de Carole) en ningún momento «corten», como dice Eisenstein, la verdadera función de la secuencia: mostrar el primer paso hacia una locura de repulsión sexual masculina por parte de Carole.

Otro ejemplo teórico que también es aplicable para esta interpretación es Pudovkin y su visión del uso del montaje sonoro. En concreto y acerca de este, extraemos esta cita que a su vez incluye palabras del propio teórico ruso:

Montage is recognized by Pudovkin as a powerful means towards this end: editing is not merely a method of linking separate scenes or pieces but is a method that controls the psychological guidance of the spectator -Pudovkin says- (...) Pudovkin acknowledges that montage can effectively create a fictive, purposeful geography or temporal unity. (Sargeant, 2001, pp. 158-159).

Así pues, esa guía de la percepción psicológica a la que Sargeant hace referencia -por medio de Pudovkin-, se desarrolla también en esta secuencia a nivel formal. Porque los sonidos orgásmicos son conducidos alrededor de cada uno de los inmuebles (el armario, la lámpara, etc.) de forma que el espectador acaba comprendiendo en qué consisten esos miedos de la protagonista, el sujeto de los mismos (en este caso, el sexo masculino).

Otro dato interesante a añadir es que tanto Eisenstein como Pudovkin, unidos a Alexandrov, crearon lo que vendría a ser el manifiesto del sonido, entre otras disciplinas teóricas. En dicho manifiesto también hallamos algunas afirmaciones que se podrían aplicar al tratamiento de esta secuencia. 
Concretamente, en eso que estos tres directores y teóricos denominan «Contrapunto orquestal», explicado en la siguiente cita:

Únicamente un empleo «contrapuntado» del sonido en relación a la pieza visual del montaje puede deparar una nueva potencialidad al desarrollo y perfección del montaje. Los primeros trabajos experimentales con el sonido deben dirigirse hacia la línea de sus distinta no-sincronización con las imágenes visuales. Solamente de este modo se obtendrá la palpabilidad, que conducirá luego a la creación de un contrapunto orquestal de imágenes auditivas. (Eisenstein, Pudovkin \& Alexandrov, 1958, pp. 280-281).

Vista la afirmación, puede lógicamente entenderse que esta fue dada en los orígenes del sonido en el cine (finales de los años 20), es decir, mucho antes de la época en que se realizó esta película. Dicha película, a su vez, que a su vez tampoco, cumple con los preceptos de lo que podríamos denominar un film experimental. No obstante, estas características del contrapunto orquestal parecen cumplirse, ya que, en el caso del sonido de los orgasmos, así como en el de las campanas del anterior instante comentado, no apreciamos qué los produce, pero es que su no unión con las imágenes (lo que aquí se denomina desincronización) es lo que aporta o produce las lecturas o interpretaciones antes mencionadas. No vemos escenificado el acto sexual que produce el orgasmo, pero sí cómo este sonido humano asciende alrededor de una serie de elementos de la pequeña habitación de la protagonista. Objetos que, posteriormente, en el punto más álgido de sus enajenaciones mentales, se alzarán contra ella. Tampoco vemos el campanario ni las campanas, pero sí cómo resuenan cuando las insinuaciones sexuales del personaje de Michael se hacen evidentes en el diálogo.

A su vez, el montaje o configuración concreta de dichas sonoridades en el espacio, favorecen a la hora de reforzar la idea del cuarto de Carole como refugio de su mundo interior; dan lugar a esa «geografía útil» también presente en la cita de Sargeant.

Dicho «refugio» es una idea contraria a la que reforzaban el sonido de las campanas de la iglesia de enfrente del apartamento, al inicio de esta secuencia. Algo que como ya mencionábamos en la cita de Latorre, remite al mundo exterior, a la realidad física que la protagonista trata de evitar. Dicho contraste, parece unir el final de esta secuencia con el inicio de la misma y concluir así con la presentación de este No-Hogar y de los miedos de la inquilina de este.

\title{
3. REPULSIÓNA TRAVÉS DE LOS ESPEJOS
}

En su estudio «El significante imaginario: Psicoanálisis y cine», Chistian Metz citaba lo siguiente acerca del recurso escenográfico del espejo en el cine:

\begin{abstract}
El espejo es el lugar de identificación primaria. La identificación con la propia mirada. La identificación con la propia mirada es secundaria en relación al espejo $[\ldots]$ pero es fundadora del cine y por consiguiente primaria cuando se habla de él. Es propiamente la «identificación cinematográfica primaria. (Metz, 1977, p. 79).
\end{abstract}

A su vez, Santiago Vila cita que dicha «identificación cinematográfica primaria» es más patente en el cine vanguardista que en los films de escritura clásica ya que «alcanzan su adecuada expresión en los géneros [...]en los que el efecto de "invisibilidad" se utiliza para potenciar la narración encauzando el contenido el contenido en la denotación del discurso simbólico» (Vila, 1997, p.240). Si bien, Repulsión 
no es exactamente un film vanguardista, pero las metáforas y escenificaciones fantasmagóricas de la mentalidad de Carole no la convierten tampoco en un film totalmente clásico.

Es por ello, que puede aplicarse aquí el recurso del espejo como «identificador primario cinematográfico» de los pensamientos de Carole. Pues «Repulsión»emplea los espejos, o, mejor dicho, sus reflejos, ofreciendo una amalgama siniestra de simbologías, que si no fuera por su uso se haría bastante difícil para el receptor captar el mensaje o conectar con la protagonista y su peculiar mundo interior.

Así pues, es posible estructurar hasta dos usos esenciales de los espejos: según Carole y su hermana Helen. Con respecto a Helen, en su caso su reflejo en los espejos es meramente superficial, definiéndonos así su egocéntrico y atrevido carácter. Ella no siente repulsión hacia el sexo contrario, ni vive con tanto sufrimiento la presencia de los hombres. Sus reflejos son amplios (Foto 8) y no están tan «deformados» como los ángulos en los que se refleja Carole. El reflejo posterior de esta en una cafetera es deforme e indefinible igual que su mentalidad (Foto 9). Este desanimado reflejo se produce precisamente, después de que Michael se lleve a la hermana de su casa.
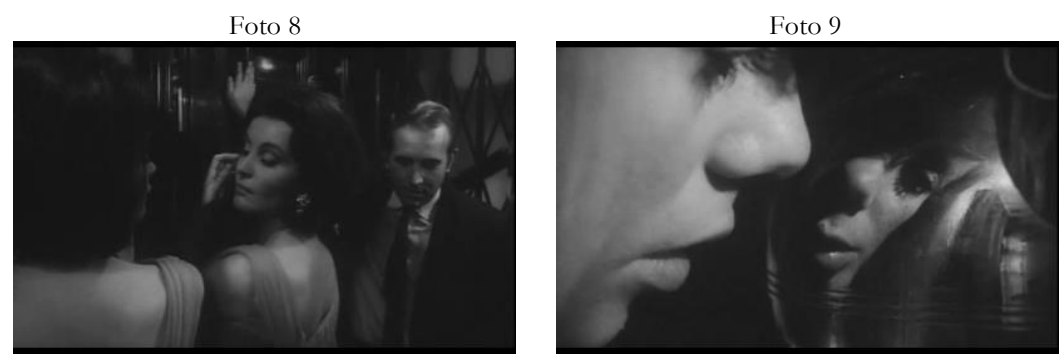

Fuente: Capturas de pantalla del DVD de «Repulsión». Edición «Fnac», Distribuidora «Avalon».

Esta situación puede verse como un indicador de que el reflejo en la cafetera alude al temor que siente hacia sí misma al hallarse sola. Por ello cabe suponer que aún no ha comenzado su declive emocional. No en vano, el espectador sigue dentro de la primera secuencia en el interior del apartamento, cuando aún se le presenta al personaje.

Volviendo al tema del espejo como «identificación cinematográfica primaria», es cierto que la cámara permanece invisible a ojos del espectador; es decir, su presencia no es «protagonista», cosa que sí pasaría en un film vanguardista propiamente dicho. Para comprenderlo mejor, un ejemplo de este tipo de films sería «Pierrot el loco» de Jean Luc Godard, donde en determinadas secuencias se «traspasaba la cuarta pared» y el personaje de Marianne (Anna Karina) comentaba y pedía la opinión del publico receptor que apreciaba la película, el «espacio imaginario» u «olvido estético» se disolvían por la presencia evidente de la cámara.

Sin embargo y retornando al film «Repulsión», es en esa angulación deforme que hace la cámara sobre la imagen en la Foto 9 y el ángulo plenamente simétrico de la «Foto 8», lo que sugiere estas teorías. Sin esos efectos que «solo» puede hacer la cámara, serían más difíciles o inexistentes estas lecturas. Es por ello que el film dirigido por Polanski se situaría en un terreno intermedio entre «vanguardista» y «clásico»; y es por ello también que se puede aplicar el apelativo de «identificador cinematográfico primario» a este uso de los reflejos del espejo.

El siguiente uso de los espejos en el film se puede observar avanzada gran parte de la película. En esta escena el reflejo sirve para mostrar los miedos de la muchacha: les da una forma humana concreta. 
Durante la secuencia, la protagonista se acerca al armario de la hermana y se contempla en el espejo con los vestidos de Helen, pues no son precisamente los que ella llevaría. A lo largo del film, si se presta atención, se vería cómo Helen, en contraste evidente con Carole, prefiere las ropas y tonos de maquillaje oscuros, incluso en su bata de andar por casa. Este contraste está acentuado por la faz luminosa y los vestidos blancos o de colores cálidos de Carole. Gracias a esta técnica sencilla, pero efectiva, se hace evidente el carácter excesivamente inocente de la protagonista, frente al gusto por la fatalidad erótica de la hermana.

Volviendo a la secuencia presente. Para cuando cierra la puerta (es un espejo de armario), el reflejo muestra a un misterioso obrero que está en un rincón de la habitación. Su figura surge de forma fortuita e inesperada, aunque por supuesto no se trata de un personaje real, sino de una manifestación del cerebro de Carole. De ahí que, cuando cierre por completo el espejo del armario, el obrero desaparezca.

Este uso de los espejos ha influenciado a más de un cineasta, especialmente en los thrillers de terror psicológico como este. Uno de los casos más recientes, que, dada la correspondencia entre las escenas, podría considerarse una relación intertextual es «Cisne Negro» («Black Swan», Darren Aronofsky, 2010). En la película de Aronofsky, hay una secuencia en una prueba de vestuario donde la protagonista Nina (Natalie Portman) ve multiplicada su propia imagen delante del espejo. Aparentemente se trata de un efecto lógico y hasta este momento, nada sorprendente, dado que está en la clásica decoración de laberinto de espejos que caracteriza un camerino del teatro. Sin embargo, en uno de los reflejos de ella misma, aparece de espaldas arañándose la espalda y, por un instante, dicho reflejo la mira fijamente hasta asustarla. El mismo impacto inesperado, el mismo estilo de disonancia musical, la reacción de las protagonistas y el uso de los espejos como muestrario de las obsesiones y miedos de ambas jóvenes, hacen que el espectador claramente de sus respectivas corduras y psiques (compárense las Fotos 10, 11, 12 de la izquierda con las 13, 14 y 15 de la derecha). Además, cabe considerar que ambas escenas quedan sutilmente entrelazadas a pesar de que «Cisne Negro» fuera rodado 45 años más tarde.

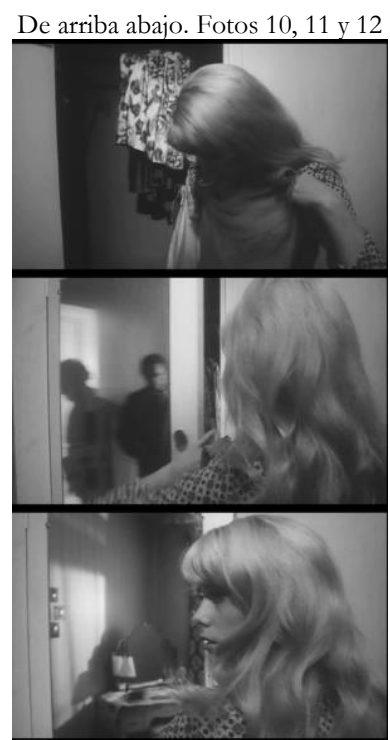

Fuente: Capturas de pantalla del DVD de «Repulsión». Edición «Fnac», Distribuidora «Avalon».

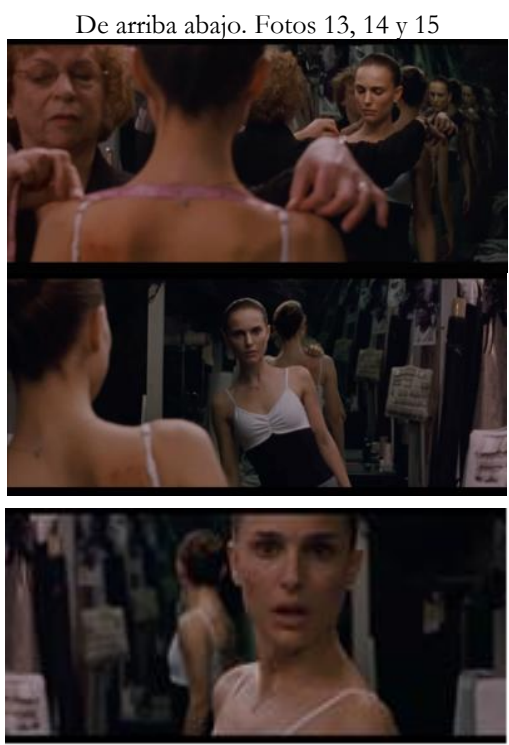

Fuente: Capturas de pantalla del DVD de «Cisne Negro». Distribuidora «20th Fox España». 


\section{UN ASESINATO ENTRE RE-ENCUADRES}

Normalmente, acorralamiento y claustrofobia suelen conformar el ambiente idóneo para provocar miedo en el espectador. Ese miedo es aún más efectivo si se manifiesta en la esquizofrénica psique del protagonista de la pantalla. Es por ello que, desde los tiempos del Expresionismo Alemán, el encuadre se convierte en el recurso técnico fundamental. de la escenografía clásica del cine de terror. Dado que un encuadre de por sí ya implica «escoger un fragmento de la realidad, seleccionar una forma de un conjunto, configurando así una estructuración significante que se propone a la contemplación del espectador» (Vila, 1992, p. 27), al re-encuadrar la imagen (es decir, encuadrar dentro de un mismo plano que ya es cuadrado por defecto) lo que consigue es crear una nueva «realidad» dentro de otra. De esta forma, la imagen fílmica se complementa con la dañada perspectiva de la realidad de la protagonista. Como se verá más adelante, las películas de Roman Polanski han seguido con esta estructura de la imagen incluso en películas que no son necesariamente de terror. Este juego de reencuadres enlazado con otros contrastes (luz-sombra, colores de ropa...) es una de las claves del «dispositivo escenográfico-psicológico» que el presente estudio se propone analizar. Para justificar esta interpretación, se tomará como ejemplo la secuencia del asesinato de Colin (John Fraser), un chico que está prendado por Carole durante gran parte de la película.

La escena del asesinato se abre con otra invasión sonora -igual a la de la presentación del apartamento en la secuencia analizada anteriormente- que es el insistente sonido del timbre unido a un fuerte golpeteo de la puerta. Carole se asoma a la mirilla de la puerta por la que se ve a Colin en primerísimo plano. En este primer re-encuadre de la escena, la cámara adquiere un punto de vista de «Ojo de Buey», una de las perspectivas habituales en las películas realizadas por Roman Polanski. Esta perspectiva provoca que el rostro de Colin se vea distorsionado, lo que una vez más pone de manifiesto esa deformante visión de la realidad de la protagonista. Asimismo, el rostro de tamaño distorsionado por el contorno y las angulaciones de la mirilla hacen que Colin parezca un monstruo (Foto 16), exactamente lo que ve la protagonista en él y cualquier otro varón.

El joven pretendiente invade el espacio íntimo de Carole derrumbando la puerta. En este sentido, podríamos decir que el uso invasivo de los «personajes exteriores» como Colin o Michael en el apartamento de esta película se acerca más a la concepción de los mismos en los films de Buñuel, donde «el personaje exterior es el representante de las pulsiones, que procede al agotamiento físico del medio considerado» (Deleuze, 1984, p. 187) que a la del personaje exterior en los films de Pasolini, en los cuales aparece «como agente sobrenatural o demostrador espiritual» (Deleuze, 1984, p.187). Sin embargo, la segunda de estas concepciones - la de los films de Passolini- sí se da en otro film de Polanski: «La semilla del diablo» (1968) con la entrada sugerida del «demonio» en la secuencia de la pesadilla de la protagonista.

Para visualizar claramente el grave alcance de esta invasión, se recurre a un continuo plano americano fijo (Foto 17) durante varios minutos, remarcando así la tensión del momento. También surte efecto gracias a un continuo juego de contrastes: vestimenta negra de Colin frente al camisón blanco y transparente de Carole, la iluminación centrada en Carole y Colin en penumbra o contraste de alturas entre ambos, ya que Colin se halla más cerca de la cámara, mientras que nuestra protagonista, al estar más alejada, parece más pequeña. Otro matiz relevante es la casi ausencia de movimiento de la protagonista, quien no sale del leve hueco conformado por el lado izquierdo de la puerta y la pared.

Una vez más, debemos remitirnos a Alfred Hitchcock y un análisis sobre este que realizaron Bordwell y Thompson con respecto a la película «Sabotaje» («Saboteur», 1942). En dicho film, el juego de picados y contrapicados de la secuencia de La Estatua de la libertad da lugar a que «el suspense de la escena deriva principalmente de la drástica diferencia entre la visión amplia [...] y la ampliación casi 
microscópica» (Bordwell y Thompson, 1979, p. 216). Lo mismo sucede con el juego de tamaños y escasos movimientos de las figuras de Carole y Colin en el escenario, primero agrandando a Colin frente a Carol y luego al viceversa (de nuevo, Foto 17). Esto puede causar una tensión continua en el espectador, pues no llega a saberse hasta el momento del asesinato quién se impone sobre quién. Aunque aparentemente se trate de una conversación amistosa.

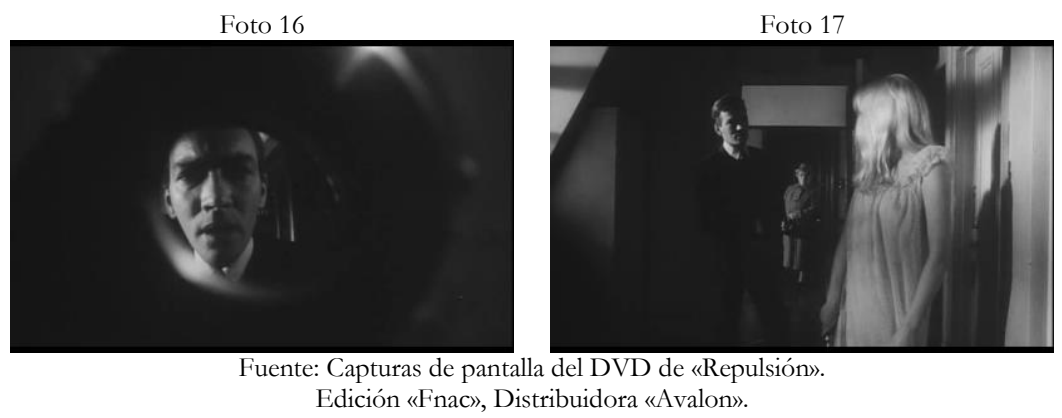

Todos estos contrastes junto con el re-encuadre diferente en que se halla Carole pueden reforzar la idea de esa «otra realidad»en la que vive Carole frente a Colin. Esta concepción de lo «real otro» de la protagonista del film se puede argumentar mediante la definición que da González Requena en su artículo «Emergencia de lo siniestro» (un adjetivo que podría ser apropiado para algunas secuencias de este film), pues encaja con la situación que se vive en este apartamento:

Definiremos la realidad como aquello del mundo que manejamos, que entendemos, que pensamos, que (...) nos resulta inteligible. Lo real es lo otro: lo que queda fuera, lo que está siempre excluido del orden de los discursos. [...] Lo absolutamente otro. Es posible una definición más sencilla: lo real es lo que se deduce del hecho, asumido radicalmente de que el mundo no está hecho para nosotros [...]. Pues bien: en el texto siniestro, es la realidad lo que se quiebra. Y es la experiencia de esa quiebra lo que nos sitúa en el campo de lo siniestro. (González Requena, 1997, p. 56).

Basándonos en la parte sencilla de la definición, como explica Requena, Carole asume que las formas de relación «hombre-mujer» en la vida diaria no están hechas para ella, esa agonía diaria es su «real otro» (el de ella, no el del espectador que percibe estas imágenes). De ahí, que la escenografía del film parezca sugerir a Colin y a cualquier otro hombre como un «monstruo».

Retomando otra vez la cita y, en concreto, el final de la misma, cuando habla del resquebrajamiento de la realidad. «Repulsión» al ser una película de género terrorífico-psicológico, supone ser también un texto «siniestro», y en el que, como tal, la realidad se «quiebra» en él. De ahí, que se pueda sugerir que la entrada de Colin en el apartamento en esta escena concreta, como si de una invasión se tratase. Esto también se puede interpretar de forma mucho más gráfica en el grupo de secuencias donde las paredes del apartamento-refugio se «agrietan» constantemente, es decir, que se «quiebran» literalmente, como en el texto siniestro del que habla González Requena.

Sobre esta cuestión de las grietas volveremos a tratar en el penúltimo punto de este estudio. De momento, se retoma la secuencia del asesinato. Si en dicha secuencia hubiera que resumir la disposición de los elementos arquitectónicos en una frase, esta sería «la claustrofobia hecha plano», ya que la 
sensación de aislamiento de los re-encuadres parece manifestarse expresamente en esas puertas de cristal cerradas y en las cortinas sin correr (lo mismo con el tabique diagonal que vemos al lado de la ventana). Todos estos detalles nos ayudan comprender qué motivación opresora lleva a Carole a asesinar a Colin, asestándole en la cabeza con un candelabro cogido previamente.

Una vez más habrá que remontarse al estilo de las películas de Alfred Hitchcock, pues en esta escena de «Repulsión» aparece, colocada en el centro de la composición audiovisual, el personaje de la vecina cotilla y su perrito que constituyen un detalle anecdótico y distractor (Véase la Foto 17). Cabe notar que se trata de otro juego de contrastes: el del leve momento cómico -la habitual vecina mayor y cotilla, clásico de las «sitcoms» que transcurren en apartamentos- con el asesinato. Esto deviene en una especie de «Mcguffin» mortal (y de ahí la referencia a Hitchcock). La combinación cómica (por el detalle de la anciana cotilla) de este momento con el asesinato es sin duda más impactante que el propio hecho de que se acaba de cometer un crimen. Una vez más la escenografía ha participado en este suceso de forma notable tanto cinematográfica como psicológicamente. El dispositivo que se analiza aquí parece haber surtido su efecto.

En un momento dado, se cambia directamente de plano y pasamos a la mirada subjetiva de lo último que ve Colin. En este caso, a la influencia de Alfred Hitchcock por el uso de ese detalle mortal, podría añadirse la de Luis Buñuel. En «Los Olvidados» (1950) la imagen recurría a «agredir»al enunciatario del film (es decir, los espectadores) por medio del lanzamiento de un huevo hacia la cámara. En la secuencia presente, el plano subjetivo de Colin nos permite ver claramente a Carole «asestándole» a la propia imagen (Foto 18). He aquí, la relación. En esta cita, se puede apreciar la explicación de dicha «agresión» de la película de Luis Buñuel, que puede enlazarse con la «agresión» que se ve en esta película de Roman Polanski:

(...) Y ello porque el enunciatario, instalado, afirmado ya en el enunciado, resulta agredido después al serle arrojado a través del personaje, un huevo; huevo que, estrellándose contra el observatario, esto es, contra la mirada a través de la que el enunciatario ve hacer, llega incluso a impedir por momentos la visión de éste. (Poyato Sánchez, 2006, p. 173).

En la secuencia de «Repulsión», el suceso se produce de forma menos violenta que en la película mexicana; pese a que se trate de un asesinato y no de un acto de vandalismo, un acto en principio más terrorífico, en términos se moralidad. También está la sutil diferencia de que en «Los Olvidados» no vemos realmente al agresor que lanza dicho huevo (por lo que la acción la haría el propio enunciador) y en «Repulsión» si vemos a Carole claramente realizar la embestida hacia Colin. Es en la «agresión»a la propia imagen donde se puede establecer ese grado de unión.

Por otra parte, en lo que atañe al tema de este estudio, la escenografía es testigo y participante de la situación. Cuando el espectador contempla la escena desde la mirada subjetiva del personaje de Colin, ve solo la puerta blanca. Cabe señalar que el color blanco de la puerta puede hacer referencia a la inocencia de Colin, «empapada» ahora de su propia sangre. Este contraste de la sangre con el blanco de la puerta, permite insinuar que la propia inocencia de Colin respecto a Carole -así como la ignorancia hacia sus demonios internos- ha sido la verdadera responsable de su muerte (Foto 19). 


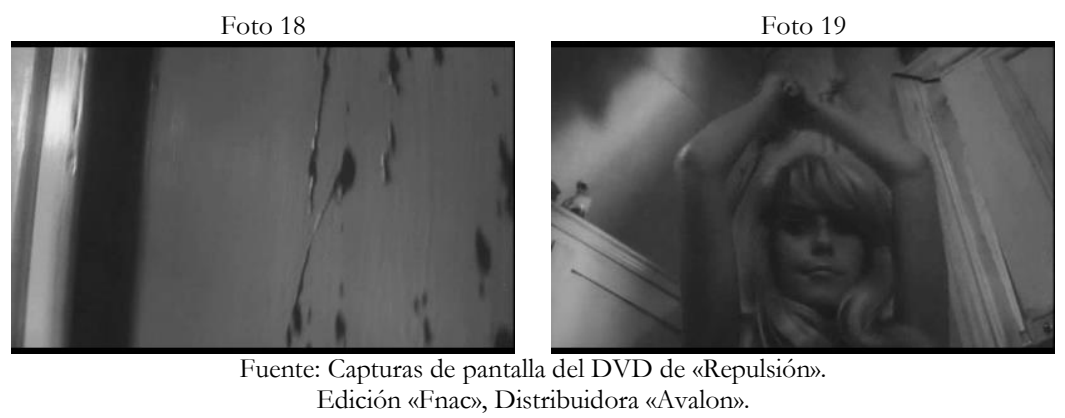

Con frecuencia, la bañera sobre la que reposa Colin, ha sido interpretada como un espacio de purificación y como tumba de agua para el personaje de Colin. Sin embargo, cabe destacar como el uso de la bañera también lleva a conformar el cuarto re-encuadre en la secuencia y que además obedece a esa obsesión estilística- claustrofóbica que ya se ha visto varias veces hasta ahora.

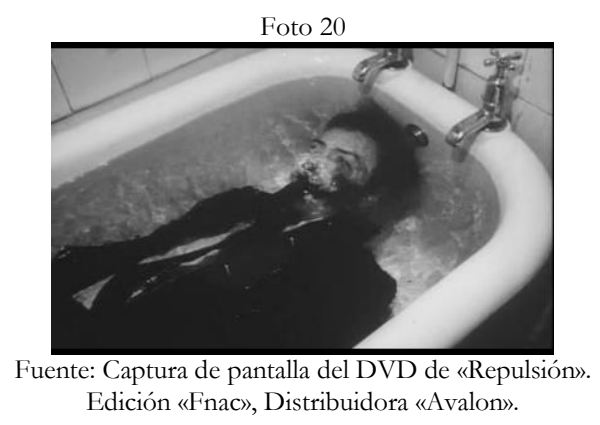

Concluye así esta secuencia y también este punto del estudio. Pero antes conviene compilar aquí, (para que quede aún más claro) los cuatro re-encuadres de la secuencia que aluden a esa claustrofobia general que envuelve la atmósfera del apartamento este momento:

- El primer re-encuadre a través de la mirilla, que nos sugiere una visión más monstruosa de Colin (Foto 16). Lo citamos como re-encuadre ya que, pese a la forma circular de la mirilla, la visión de esta supone un segundo ajustamiento más dentro de los cuatro lados del plano

- El segundo re-encuadre es el del hueco entre la puerta y la pared de Carole no se mueve. Una segunda dimensión cuadrangular dentro de un plano ya cuadrado por defecto. (Foto 17).

- De forma simétrica y, en segundo término, la vecina que estaba situada en el centro de la composición del largo plano mencionado anteriormente. Su alejamiento la volvía mínima ante los ojos del espectador. (También en la Foto 18).

- Y finalmente cuando Colin queda «encajado» en la pequeña bañera, una «bufanda» de sangre que se forma alrededor de él, hace que el espectador pierda su percepción de este personaje. (Foto 20).

Al poco de producirse el asesinato, Carole en lugar de retirar el cadáver del apartamento, prefiere fortificar el espacio con maderas y clavos; con ello demuestra que prefiere seguir encerrada en ese apartamento que recibir el contacto de hombres. Ella misma sabe que está en medio de un abismo psicológico, pero prefiere seguir dentro de dicho abismo porque ve refugio donde los demás no lo 
ven; por ello refuerza la seguridad en la puerta principal de la vivienda. Esta acción admite revelar una posible metáfora escenográfica de vital importancia: la del «No-Hogar» como figuración arquitectónica del cerebro de Carole. Se trata de una lectura muy parecida a la que también se recurrirá tres años después en el apartamento de Rosemary para «La Semilla del diablo» («Rosemary’s Baby», 1968). En ella, se podía establecer una analogía entre el edificio Bramtford con el vientre materno de la protagonista, ya que es donde Rosemary (Mia Farrow) «va a ser fecundada [...] y por tratarse del lugar al que los personajes siempre retornan» (López Villarquide, 2006, p. 19).

\section{GRIETAS Y MANOS}

En 1985, en auge de la publicación de su primera y hasta el momento última autobiografía, Roman Polanski comentaba esto acerca de sus intenciones escenográficas con respecto a «Repulsión»:

Mi propósito era mostrar las alucinaciones de Carole a través del ojo de la cámara. Realzando su impacto por medio de lentes gran-angulares o bien de la ampliación progresiva de campo. Sin embargo, eso sólo no bastaba para lo que yo pretendía. Quería alterar, además las dimensiones efectivas del apartamento: ensanchar las habitaciones y los pasillos y retirar las paredes para que los espectadores pudieran experimentar todo el efecto de la deformada visión de Carole. Para ello, diseñamos las paredes del decorado de tal forma que se pudieran mover hacia fuera $y$ alargarse mediante la inserción de paneles adicionales. Cuando se 'estiraba' de esta manera, por ejemplo, el estrecho pasillo que conducía al cuarto de baño, adquiría unas proporciones de pesadilla. (Polanski, 1985, p. 240).

Teniendo en cuenta las declaraciones de Roman Polanski con respecto a lo que se intentó hacer en el film y de acuerdo con el objetivo de este estudio, se analizarán dos secuencias que responden a una serie de visiones surrealistas muy características de una mente tan dañada como la de Carole Ledoux. De esta forma, las imágenes establecen así un paralelismo entre ese daño de la mente y el estado de la arquitectura. La forma física en la que lo hacen, es mediante una serie de grietas que se van produciendo conforme la mente de Carole va degenerando. Ya habíamos hecho referencia a estas grietas, en el punto anterior, cuando hablábamos de la quiebra de la realidad en el texto siniestro, al que se refería González Requena.

En dos secuencias del tramo final, las grietas se multiplican dejando salir de entre ellas una serie de manos viriles que atrapan y bloquean al personaje. Asociación más que evidente de cómo las tan repudiadas masculinidades estrujan el mundo interior de Carole.

De los dos aprisionamientos de manos, el primero tendrá lugar en la escena en la que la iluminación adquiere un tono clara y enésimamente heredado del expresionismo alemán, principalmente por el detalle de centrar completamente el foco en la puerta del baño (Foto 21), pero sobre todo por ese primer plano que ilumina el rostro de Carole, y en concreto uno de sus ojos, signo inequívoco de que lo que vamos a apreciar se halla dentro de su cruenta (con ella misma) imaginación. (Foto 22). 


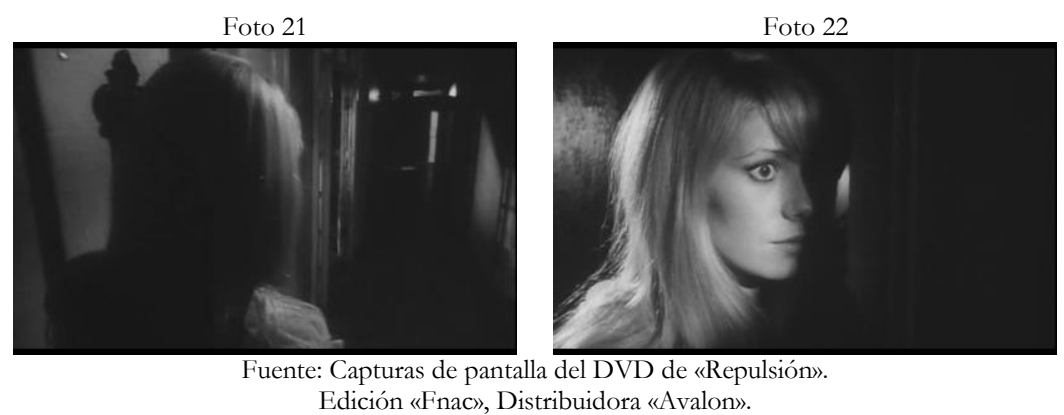

La inestabilidad como rutina hogareña es un detalle que se parece mantenerse hasta en los más mínimos cimientos, como se puede apreciar en el caso del fino hilo interruptor que se tambalea constantemente frente a la faz de la cara de la protagonista (Foto 23). Una pincelada que puede interpretarse como la extrema delgadez de la línea que separa la realidad de la fantasía para ella. Por tanto, la colocación del rostro de Carole en medio del hilo la sitúa en la frontera entre ambas.

Se recurre al cambio drástico de atmosfera: el baño antes blanco, alicatado y que para la protagonista servía casi de ritual de purificación «de la realidad de fuera» (ver punto 2 «Presentación: Invasión sonora del No-Hogar en Futura descomposición»), ahora está rodado de tal forma que parece aún más pequeño. No es blanco, sino negro que a la de un baño corriente cualquiera de cualquier casa. No se ven los alicatados y obedece más a la disposición de una pequeña gruta (foto 24). Parece como sí las gotas de agua que caen del lavabo salieran de unas rocas y llama la atención la escasa iluminación que deja la huella de la puerta.

Cabe señalar que no debería sorprender el uso de este tipo de distorsiones de la imagen, pues ya se advertía en el plano de la imagen facial de Carole distorsionada en la tetera. (Punto 3 «Repulsión a través de los espejos»). Esto demuestra cómo toda la escenografía está perfectamente conectada entre sí, lo que evidencia la efectividad de ese «dispositivo escenográfico-psicológico» al que se aludía en la introducción de este ensayo.

Por otra parte, a este uso de la perspectiva del baño es lo que Bordwell y Thompson denominan perspectiva lineal descentrada «donde el punto de fuga no es el centro geométrico» (Bordwell y Thompson, 1979, p. 168). Dicha disimetría escenográfica aumenta esa sensación de locura y la posibilidad de que estamos viendo una realidad distorsionada, más allá de lo propiamente cinematográfico.

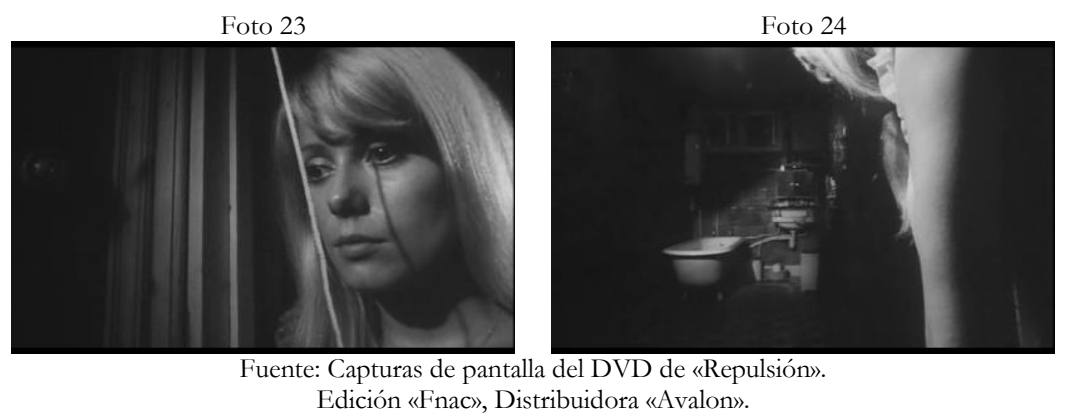


Otra manifestación que se usa en la película «Repulsión», para especificar que el espectador se halla dentro de la demencial cabeza de Carole, es que el cadáver de Colin no aparece en la bañera y que esta ni siquiera está llena de agua como la última vez que se vio. También puede transmitir cierta exasperación, el hecho de que se muestren las articulaciones del baño: cadenas de tuberías y cañerías entre el lavabo y la bañera que antes no se distinguían, y que ahora, al final -tanto del film como de la cordura del personaje- se aprecian con claridad.

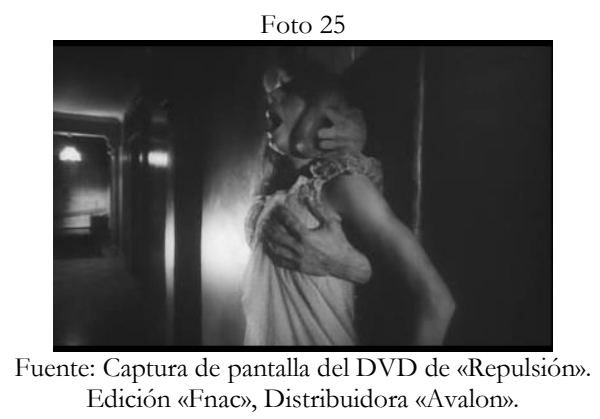

Carole se aparta hacia la pared de la que sale una leve grieta y de esta, a su vez, una mano que la agarra (Foto 25). Ella se aparta, apoyándose en la pared anexa, de donde salen inexplicablemente otras tres manos que le aprietan fuertemente el pecho y el rostro en clara señal de violación. La masculinidad se ha apoderado definitivamente de ella por medio de este gesto impúdico, como bien cita Guillem Reig en su estudio sobre el film.

Carole solo está segura y tranquila en la medida en que el lugar (refiriéndose al apartamento) reproduce la sensación protectora del seno materno. Su hipersexualidad, su miedo y deseo a la vez, hacen que necesite de un lugar cerrado como refugio y lugar donde poseer a las futuras víctimas. Por esto sus peores delirios son los que le presentan a la vez el derribo de los muros y su transformación en brazos acariciantes. (Reig, 1975, pp. 6-7).

El segundo Aprisionamiento de las manos aparecen en la siguiente escena que tiene un ritmo parecido al de la anterior. Recurriendo a un plano-secuencia, la imagen capta al personaje de Catherine Deneuve, quien da vueltas alrededor de sí misma en el salón-comedor. Las dimensiones de dicho habitáculo se amplían monstruosamente como ocurría en el baño (Foto 26). Las expresionistas iluminaciones de las ventanas vuelven a orientar a la trastornada mujer hacia las -ahora estrechas- paredes del baño de las que vuelven a salir, en un plano general, múltiples manos. En esta ocasión, todos los brazos forman un interminable bosque de articulaciones que tratan de atrapar a la protagonista (Foto 27). Ella finalmente se entrega, dejándose atrapar por ellas en señal de rendición. 

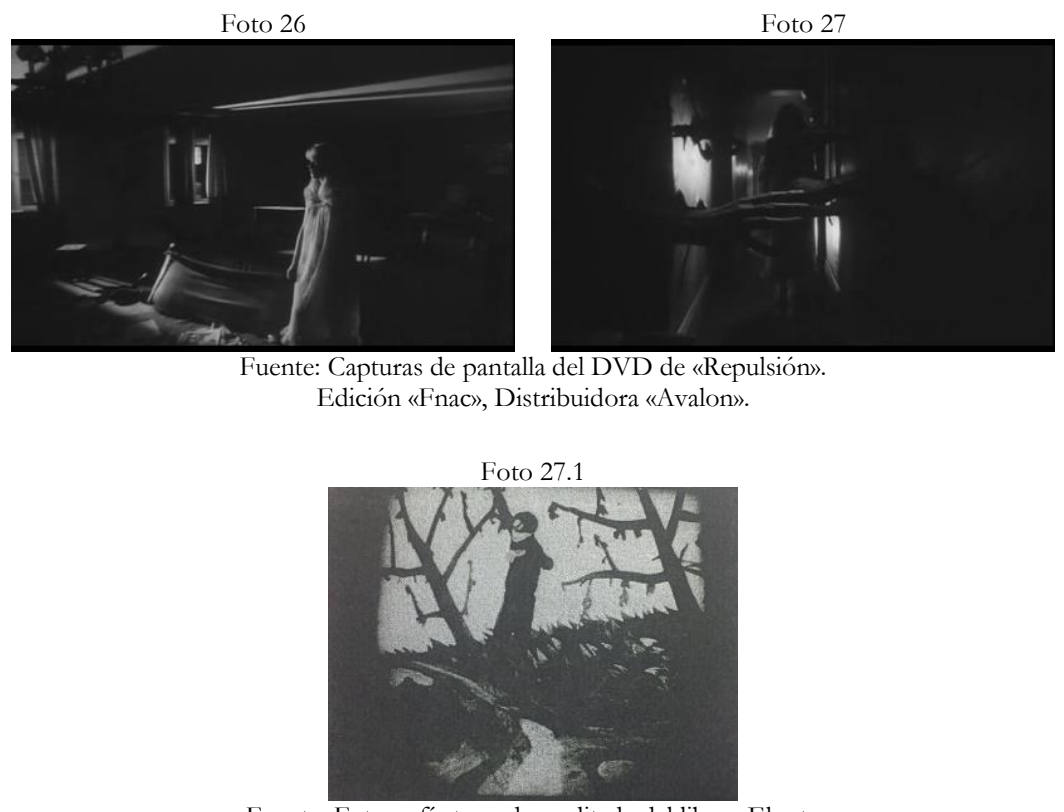

Fuente: Fotografía tomada y editada del libro «El arte cinematográfico», de David Bordwell y Kristin Thompson.

Llegados a este punto, hemos apreciado una serie de influencias para este estudio del film, de las que podríamos citar hasta tres nombres: Augé (a nivel de terminología y de cara al concepto «NoHogar»), Luis Buñuel -en la «agresión» visual antes narrada e incluso en algún giro surrealista como la acción de los brazos, pero esto puede atribuirse casi por defecto profesional- y Alfred Hitchcock en determinadas tomas de imágenes -la toma fetichista de los pies a ras de suelo y el juego de tamaños y superposiciones que contribuye al juego del suspense-. Aunque se viene antecediendo desde hace algunas líneas, no es negable el posible influjo expresionista alemán, bien por defecto (es el juego lumínico clave en las películas de terror más clásicas) o bien en la siguiente toma del escenario. Nos referimos al ya citado plano de los brazos (Foto 28) que posiblemente emane de varios de los planos de uno de los títulos fundacionales de la corriente muda alemana: «El gabinete del Doctor Caligari» (Robert Wiene, 1922), en concreto aquellos en los que las ramas de los árboles se extendían cual brazos humanos «sintonizando» con el protagonista en un juego interpretativo característico de esta corriente estética (Foto 27.1). Pues bien, la interpretación de Catherine Deneuve que «a diferencia de la de Conrad Veidt del sonámbulo Cesare hace que se mezcle con los elementos gráficos del decorado. Su cuerpo imita los inclinados troncos de los árboles, sus brazos y manos las ramas de las hojas» (Bordwell y Thompson, 1979, p. 161); no es, ni mucho menos, una interpretación «expresionista». Es, de hecho, una interpretación bastante contenida, sin embargo, al igual que en el plano «El gabinete del doctor Caligari», es «el bosque de manos» el que «sintoniza» con la protagonista en un juego similar, pero al revés de la película muda. Ya que las manos, aunque efectúen una acción de «atrapamiento», dejan un leve espacio a ella se ajustan a las proporciones del cuerpo en el espacio. Como si el propio apartamento «hermanase» con ella en algún sentido. Dicho de otro modo, en el film de Polanski, es el escenario quien se funde con la figura de la protagonista, mientras que en el film de Wiene, es el protagonista quien se funde con el tétrico escenario. 
Esta acción se complementa con el siguiente momento de la secuencia cuando la imagen pasa a un fundido a negro que lleva directamente al espectador al paraje de la habitación de Carole que conocimos en el punto 1. En la secuencia, la cámara recurre a una vista con focal corta que capta la lámpara del techo de la habitación, de manera que parezca aún más monstruosa (Foto 28), otro efecto muy parecido al de la mirilla de la puerta cuando esta capta el rostro de Colin como un monstruo (Punto 4 «Un asesinato entre encuadres»). La manera en la que la cámara enfoca la lámpara, hace que parezca que la propia Carole se funda con la terrorífica arquitectura del no-hogar. Cabe interpretarlo como una metáfora plástica absoluta del personaje «ahogándose» definitivamente en su propia locura. Así, esta escena se encadenaría con la primera secuencia de la habitación; cuando esta se «contagiaba» sonoramente de la esencia masculina.

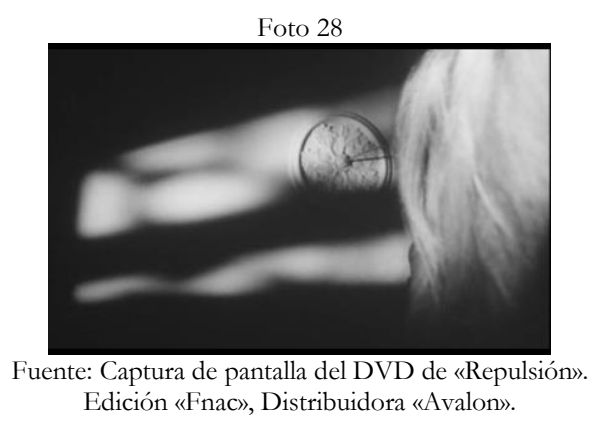

\section{CONCLUSIÓN}

Hasta aquí, se puede sostener que, a lo largo del film, las imágenes consiguen sobrecoger al cinéfilo a base de constantemente metaforizar con la retorcida mente de Carole Leodux. Tal efecto es logrado en gran medida gracias a cómo la historia juega a que los que rodean a Carole confundan su silenciosa vulnerabilidad y su belleza con la dulzura e incluso con una timidez exagerada. Esto es así en cuanto a nivel temático. Pero es sin duda el programa escenográfico-psicológico aquí abordado el que se erige como núcleo de la riqueza plástica y teórica de la película. Este programa consiste en crear una atmósfera cada vez más opresiva por medio de los elementos escenográficos más simples. Al principio se trata de detalles más sencillos tales como los sonidos (ya sean los del amenazante exterior o los producidos por la propia masculinidad). Luego los primeros síntomas de esa divagación mental de la protagonista se muestran mediante los reflejos: ejemplos indiscutibles los proporcionan el instante del reflejo de la cafetera o la visión frente al armario. Avanzada la película, los miedos del espectador y de la protagonista se enclaustran en la cruel secuencia del asesinato, lo que se manifiesta en un uso cada vez mayor del re-encuadre cinematográfico complementado de la mirada subjetiva de la víctima. El programa escenográfico se cierra en esta película con las dos secuencias en las que, gracias a las ventajas del medio cinematográfico, el alegórico uso de las alucinógenas grietas y manos de la pared concluyen apresando irremediablemente a nuestro personaje en la secuencia del techo del cuarto de Carole.

Es importante observar cómo esta progresión escenográfico-psicológica se ha depurado y desarrollado en Repulsión primeramente y en La semilla del diablo (1968) y El quimérico inquilino (1976) posteriormente. Sin ellas, hubiese sido bastante difícil esta concepción en imágenes, apreciable en películas posteriores de la filmografía de Polanski como Tess (1979) y El pianista (2002). Porque, pese a que pertenezcan a diferentes géneros (terror psicológico frente a drama histórico), en ambas se ven ese efecto terrorífico y escénicamente claustrofóbico abordados en este estudio, pero adaptados al nuevo 
género de estas películas. Uno de los ejemplos más notables lo ofrece el final de Tess (1979) y el instante aquí analizado de la primera secuencia en el apartamento de Repulsión. En ambas escenas, los alrededores «encierran» a los personajes anticipando su destino fatal. Como se ha mencionado anteriormente, la escena de Repulsión (Foto 29) presagia los primeros brotes de locura de la protagonista. En el caso del final de Tess (Foto 30), la jaula de piedra que conforma el Cromlech de Stonehenge anticipa la detención de la pareja protagonista por la guardia inglesa a la mañana siguiente. Lo único que diferencia a ambas es la atmósfera expresionista de Repulsión -por las angulaciones y marcados contrastes lu₹/sombra del film analizado en este escrito- aquí se recurre a una ambientación más propia del luminismo de los cuadros románticos; así como también sucede con la preponderancia de la ruina y la relación de los sentimientos con la naturaleza, de la adaptación de la novela de Thomas Hardy. Todo ello pone de relieve la necesidad de comprender y analizar este estilema opresivo que constituye la delgada e invisible línea que encadena gran parte de la filmografía de Polanski

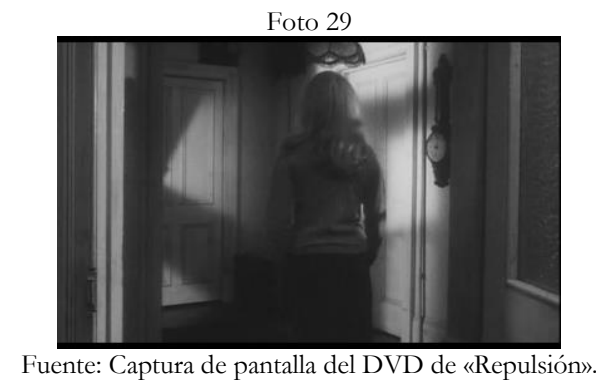

Edición «Fnac», Distribuidora «Avalon».

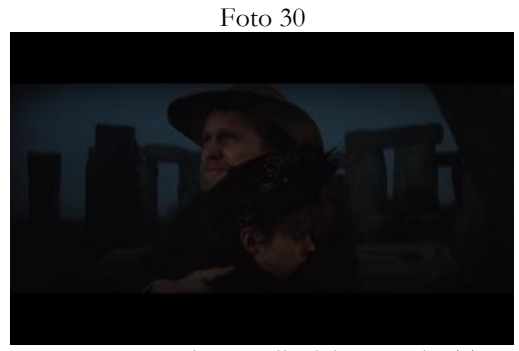

Fuente: Captura de pantalla del DVD de «Tess». Distribuidora «Avalon».

\section{BIBLIOGRAFÍA}

Augé, M. (1992). Los no-lugares. Espacios del anonimato. Una antropología de la sobremodernidad. Barcelona: Ed. Gedisa

Avron, D. (1990). Los colosos del cine: Roman Polanski. Barcelona: Cinema Club Collection.

Bordwell, D. \& Thompson, K. (1979). El arte cinematográfico: Una introducción. Barcelona: Ed. Paidós Comunicación

Deleuze, G. (1984). La imagen movimiento. Barcelona: Ed. Paidós Comunicación.

Eisenstein, S. M Pudovkin, V. \& Alexandrov, G. (1958). Manifiesto del sonido. En S. Eisenstein (Ed.), Teoría y técnicas cinematográficas (pp. 277-281). Madrid: Ediciones Rialp S.A

Eisenstein, S. M. (2001). Hacia una teoría del montaje, Vol. 2. Madrid: Paidós Comunicación.

Latorre, J. M. (1998). En la oscuridad: breve antología crítica. Cáceres: Asociación Cinéfila de Cáceres Re-Bross. Moldes, D. (2004). Roman Polanski: La fantasía del atormentado. Madrid: Ediciones JC.

Polanski, R. (1985). Roman por Polanski. Barcelona: Grijalbo.

Poyato, P. (2006). Circuito enunciativo de agresión y mundo Originario en «Los olvidados» de Buñuel. Pandora: revue d'etudes hispaniques, 2, 171-185 Recuperado de https://dialnet.unirioja.es/servlet/articulo? codigo $=2567378$

Reig, G. (1975). Estudio sobre Roman Polanski. Dirigido por, 19, 1-12.

Requena, J. G. (1997). Emergencia de lo siniestro. Trama y Fondo, 2, 51-75. Recuperado de https://dl.dropboxusercontent.com/u/60156832/numeros revista/Trama y Fondo 2.pdf

Sargeant, A. (2006). KINO - the Russian Cinema: V sevolod Pudovkin: Classic Films of the Soviet Avant-garde. London, US: I. B. Tauris, 2001: http://site.ebrary.com/lib/bibliocordoba/reader.action?ppg=181\&docID=10133128\&t $\underline{m=1480422801679}$ 
Vila, S. (1997). La escenografia: cine y arquitectura. Madrid: Catedra S.A

Villarquide, M. L. (2006). Roman Polanski: Visiones siniestras de lo cotidiano. Cuadernos de documentación Multimedia Universidad Complutense de Madrid, 17, 26-52. Recuperado de http: $/ /$ multidoc.rediris.es $/ \mathrm{cdm} /$ include $/$ getdoc.php?id $=233 \&$ article $=44 \&$ mode $=$ pdf\&

OJSSESSSID $=\mathrm{b} 35700 \mathrm{bf} 06 \mathrm{ed} 5 \mathrm{ab} 38 \mathrm{~cd} 8 \mathrm{eeeb} 645 \mathrm{de} 400$

\section{Fonseca, Journal of Communication}

